\title{
The Autumn Leaf
}

From "THE MINNESOTA NATURALIST"

$\mathbf{N}$ ATURE knows no half measures and nothing in her changing seasons becomes her like the leaving of them. Massed in harmonious blend are the deep reds of the sturdy oaks. Maples are legion' with shades of crimson; cardinal, coral, salmon and yellow. Sassafras boasts of orangered and tangerine; birches and aspens dazzle with the richness of burnished yellow or old gold while the leaves of the handsome ash are pasteled with plum and grape and orchid.

If man could create a leaf the mystery of the universe would be solved. It would surpass any of his achievements to date-for a leaf is the basis of all ife. It feeds the plant which feeds mankind and it sustains the animals which form the food of mankind. Even the carniverous animals must depend for sustenance upon those animals which in turn live upon our vegetation. Without a leaf life would soon cease to exist.

Would it destroy some cherished legend or spoil things if the story of an autumn leaf were unfolded and found to contain no deep mystery in its yearly color changes? And what about old Jack Frost who in his natural modesty has never made a claim but who has been credited through all the years with having, by a touch of his magic wand, performed an overnight miracle in the color world? Would one think any the less of him to know that there is no more mystery in the color change of an autumn leaf than in any other thing in nature-and that he does not play a role in the transformation but is merely a bystander even as you and I? True it is that he is often there as a witness because his presence and the first cold nights of fall frequently coincide-an accidental and incidental presence, but never essential. What, then, does happen on these first cold autumn evenings?

The life-giving fluid, or blood, of a leaf is a green substance known as chlorophyll-a pigment which has been aptly termed the world's most potent dye. It has been estimated that some two billion tons of it are used annually in imparting the greenness to all growing plants and furnishing the vitalizing spark to the vegetable world. The chemistry of all plant life is complex and involved: botanists and plant physiologists do not always agree on the exact causes of what takes place but they do agree on certain basic principles and conclusions-especially as to what has taken place. Thus we have an explanation of what happens to a leaf as it nears the end of its life span.

The leaf has been likened to a tiny factory; a remarkable factory where only nature's raw materials are used. Here in this busy workshop, with the aid of essential light from the sun, green chlorophyll is formed-a substance which endows a leaf with the power to make starch, and sugar, and oils, from Nature's plentiful supply of water and carbon dioxide. The water with its valuable chemical salts enters the plant or tree through its fine hair roots and by various means of travel known to scientists by such strange names as osmoses, capillarity and transpiration-a sort of pipe conveyance-it ascends to the leaf factory. From the air through a myriad of microscopic doors (stomata) in the underside of the leaf, carbon dioxide is taken in. The network of leaf veins and smaller veinlets serve to deliver these raw materials to all parts of the leaf and the factory is ready for operation.

Light from the sun starts the process and with the arrival of the warm, sunshiny days, and in the presence of the master substance, chlorophyll, the manufacture of life food begins. It is called photo-synthesis. The work ceases at night for want of light but in the darkness the starches are changed to sugar, dissolved in water and, through a different set of pipelines, delivered to all parts of the plant for food, growth and storage. This, in its simplest terms, is the normal operation of each tiny factory. Without chlorophyll it cannot operate nor can the processing go on without light. All during the warm summer days the leaf is at work, from morning 
until night, in the preparation and the distribution of life-giving food to the plant or tree.

As the leaf nears the end of Summer, and its alloted span, there are many factors which contribute to its maturity and color change. The days become shorter with less and weaker light. The nights become correspondingly longer and cooler. Water with its minerals cease to run up the pipelines with usual agility. The flow thickens and becomes slower. The air and soil are drier and there is a gradual slowing down of supplies to the leaf. The tiny veinlets become clogged with waste and the deposits of unused mineral. Factory operations become tired and sluggish and the processing tapers off toward the inevitable end. It is the normal ending of a life cycle; the natural termination of the work, the purpose and life of the leaf.

Then come the still colder days and nights to hasten the end. The demise is quickened by an extremely cold night. Leaf life would cease anyway but Nature with her sudden cold gives the kindly aid to what might otherwise be a lingering death. The green chlorophyll disappears entirely, leaving exposed some of the unused sugars and pigments to glow in their own original colors of red, yellow, and purple. Chemical changes are brought about by a death pigment called anthocynin. The final waste substances and leftover pigments are capables of a thousand shades and hues. The leaf which has worked all summer must die like all living things and in dying is transfigured. The painted woods bear testimony to the completion of one more cycle. The passing is the fulfillment of a purpose-the nourishment and life of the tree. What a pity it is that all living things do not, in their departure, become transfigured with the beauty and glory of the autumn leaf.

The passing of an autumn leaf takes place where Jack Frost is unknown and rarely if ever appears. That the transfiguration is most beautiful in the northern climates is due perhaps to the colder drier air: the climate itself; the flora characteristics and many factors of plant ecology. In places where there is an early frost of heavy proportions there is little autumnal beauty for the very touch of Jack Frost's destroying power browns, shrivels and curls the dying leaf. It is his wand that throws down the leaf before it has fulfilled its final function.

How very fortunatet are those who live in the land where abound the Sugar Maples. Maples are without peer in their contribution to the brilliancy and range of color. One of our best known and much admired botanists and naturalists-Donald Culross Peattie, in his new book, "A NATURAL HISTORY OF TREES," says, "The most magnificent display of color in all the kingdom of plants is in the autumnal foliage of the trees of North America. Over them all, over the clear light of the Aspens and Mountain Ash, over the leaping flame of Sumac and the hell-fire flickerings of poison ivy, over the war-paint of the many Oaks, rise the colors of one tree-the Sugar Maple-in the shout of one great army. Clearest yellow, richest crimson, tumultuous scarlet, or brilliant orange-the yellow pigments shining through the overpainting of red-the foliage of Sugar Maple outdoes and unifies the rest. It is like the mighty, matching melody that rides upon the crest of some symphonic weltering sea and, with its crying song, gives meaning to all the calculated dissonance of the orchestra." Anonymously submitted.

\section{A Pocket Hatchery}

From the Regina Leader Post

What a small boy has in his pockets has been the subject of many a story and poem, but this one is hard to beat.

The other day, David Fox, small scn of Rev. R. Fox and Mrs. Fox in Wadena, found a sparrow's egg lying on the sidewalk. Within a second it was inside David's pocket and he was off to play.

On his arrival home David put his hand in his pocket and was amazed to find a baby sparrow. The wonderfu: discovery was carefully bedded down in a dixie cup hung by string close to the kitchen stove and the tiny bird was soon chirping so loudly David named it "Chip." 